\title{
The assessment of exploitation process of power for access control system
}

\author{
Michał Wiśnios ${ }^{1, *}$, and Jacek Paś $^{1}$ \\ ${ }^{1}$ Military University of Technology, Faculty of Electronic, Institute of Electronic Systems, 00-908 Warsaw, 2 Gen. S. Kaliskiego \\ Street, Poland
}

\begin{abstract}
The safety of public utility facilities is a function not only of effectiveness of the electronic safety systems, used for protection of property and persons, but it also depends on the proper functioning of their power supply systems. The authors of the research paper analysed the power supply systems, which are used in buildings for the access control system that is integrated with the closed-circuit TV. The Access Control System is a set of electronic, electromechanical and electrical devices and the computer software controlling the operation of the above-mentioned elements, which is aimed at identification of people, vehicles allowed to cross the boundary of the reserved area, to prevent from crossing the reserved area and to generate the alarm signal informing about the attempt of crossing by an unauthorised entity. The industrial electricity with appropriate technical parameters is a basis of proper functioning of safety systems. Only the electricity supply to the systems is not equivalent to the operation continuity provision. In practice, redundant power supply systems are used. In the carried out reliability analysis of the power supply system, various power circuits of the system were taken into account. The reliability and operation requirements for this type of system were also included.
\end{abstract}

\section{Introduction}

The basic criterion providing the power supply continuity for the access control system includes high reliability of all power supply devices forming the power grid [1-3]. The quality of the supplied electricity, which the proper functioning of a number of receivers depends on, does not remain irrelevant $[2,4,5]$. The quality parameters of electricity - supplying the electric receivers, including the biometric access control system, were determined in the relevant standards - e.g. PN-EN 50160 or regulations of the Journal of Laws No. 93/2007 [6]. The standards and regulations strictly define the electricity parameters, however, there is a lack of executive regulations, which would constitute a basis for enforcement against the receivers of interference introduced to the grid [7-9]. For the purposes of the devices forming the access control system, the most dangerous are short power interruptions and their specific cases defined as voltage dips $[10,2,11]$. In order to continue the access control system operation, in case of voltage losses longer than $10 \mathrm{~ms}$, it is important to use the emergency source of electricity, e.g. accumulators' batteries or UPS devices [12,13]. The Access Control System is a set of electronic, electromechanical and electrical devices and the computer software controlling the operation of the above-mentioned elements, which is aimed at:

- identification of people or vehicles allowed to cross the boundary of the reserved area $[14,15]$;

\footnotetext{
*Corresponding author: michal.wisnios@wat.edu.pl
}

- prevention from crossing the boundary of the reserved area by unauthorised people or vehicles [16];

- generation of an alarm signal informing about an attempt of crossing by an unauthorised entity.

In Fig. 1, a simplified diagram of the access control system used in the large facility was presented.

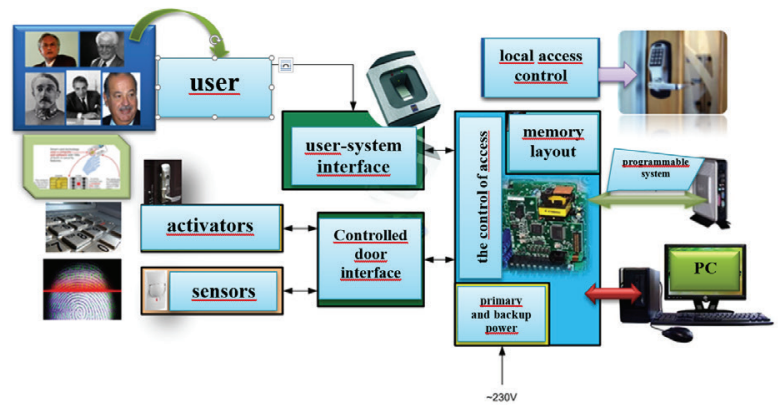

Fig. 1. Block diagram of the access control system.

Currently, in the controlled facilities, where the access control system was applied, a technique of verifying the user, which uses biometrics, is applied $[17,18,19]$. This technique allows for precise identification of individuals with the use of their unique characteristics. Initially (due to high costs), the biometric readers were installed only in the systems designed for special-purpose facilities, e.g. secret offices. The rapid development of microprocessor technologies and electronic programmable systems resulted in the situation that the price of biometric readers decreased, however, the 
operation precision and reliability increased [20-22]. In order to control the processes of passenger and transport traffic in large areas and facilities, the distributed access control systems are used [23-25] - Fig. 2. The integration of safety systems with access control systems makes it possible to introduce new functionalities - e.g. control over a moving object within the zone, possibility of blocking specific premises, creation of interactive documentation of the users' stay in a given facility, remote monitoring, archiving, overview and diagnosing of the system with the use of TCP/IP network, counting the number of objects at the entrance and exit, blocking the entrances to the zones in case of a breach of e.g. perimeter protection of the facility, etc. $[25,26]$.

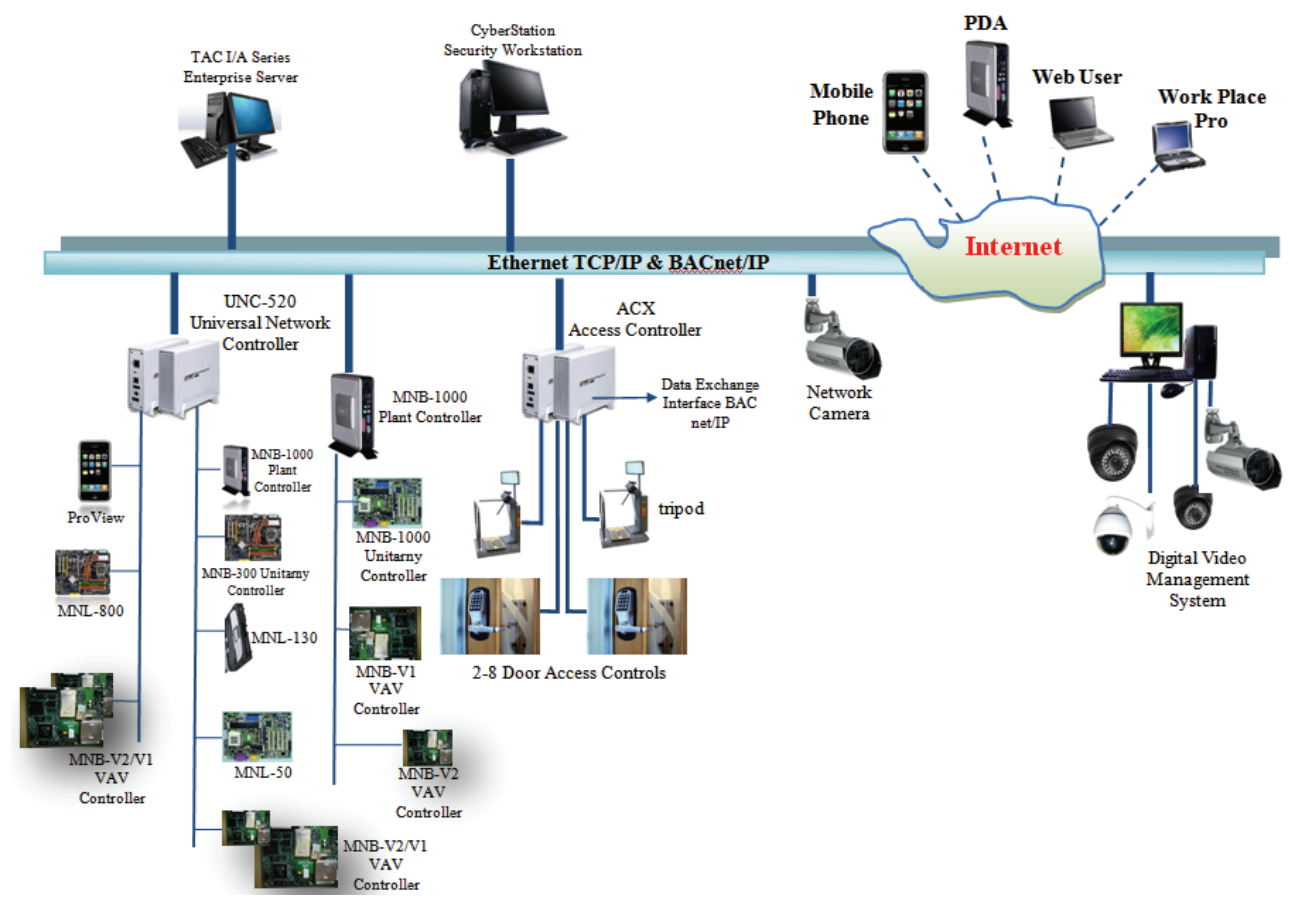

Fig. 2. Separate integrated access control system.

\section{Methods for implementation of access control systems' power supply}

The power supply of access control systems can be implemented in three different ways, which must take into account, among others, the areal extent, on which the system is placed, requirements specified in the standards and recommendations, and also the economic balance - Fig. 3 .

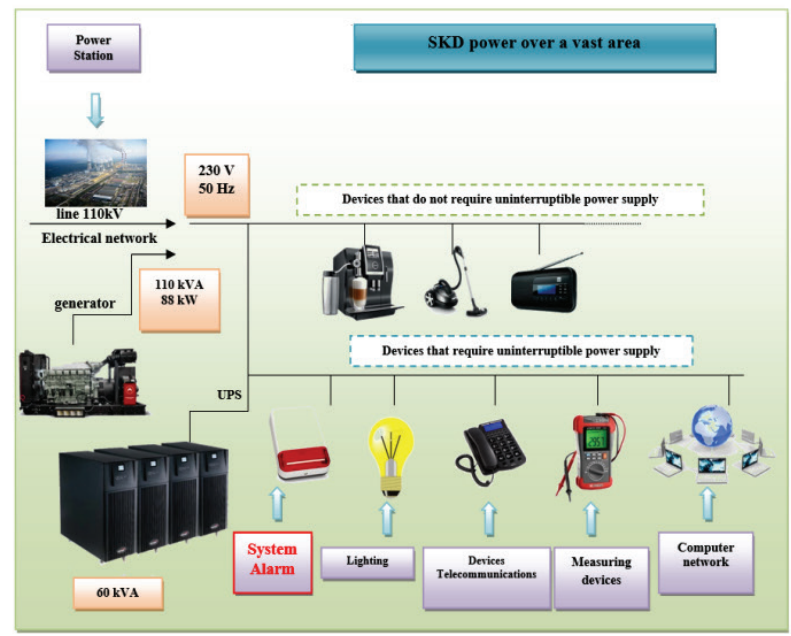

Fig. 3. Implementation of the access control systems' power supply.
The access control system's power supply can be implemented as follows:

- concentrated (power supply is connected to the mainboard - control panel, all the system's elements and devices are supplied from surveillance lines or transmission buses);

- distributed (in the system, there are many power supplies due to high power consumption by individual elements and devices, which are located at a considerable distance from the control panel - voltage drops in the surveillance lines and transmission buses from quiescent current and alarm current, all the power supplies occurring in the system should be monitored by the control panel due to sabotage and technical parameters of the output voltage - Fig. 4);

- mixed (system, due to the large areal extent, on which it is installed [27], uses at least two control panels, the concentrated system is supplied from the power supply with the use of surveillance and transmission lines, which are connected to the control panel - Fig. 5, control subpanels are supplied from other power supplies, or modules $1,2, \ldots, \mathrm{n}$ can be supplied in the system by independent power sources, like in the distributed system, all the power supplies should be monitored by the control panel due to sabotage and technical parameters of the output voltage.

The selection of a type and a method of power supply in the access control system should be preceded by drawing 


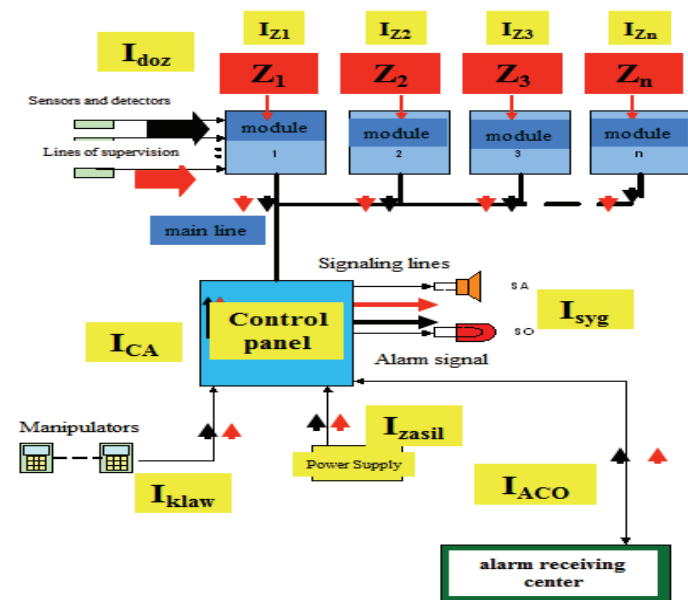

Fig. 4. Power supply implementation in the distributed access control system.

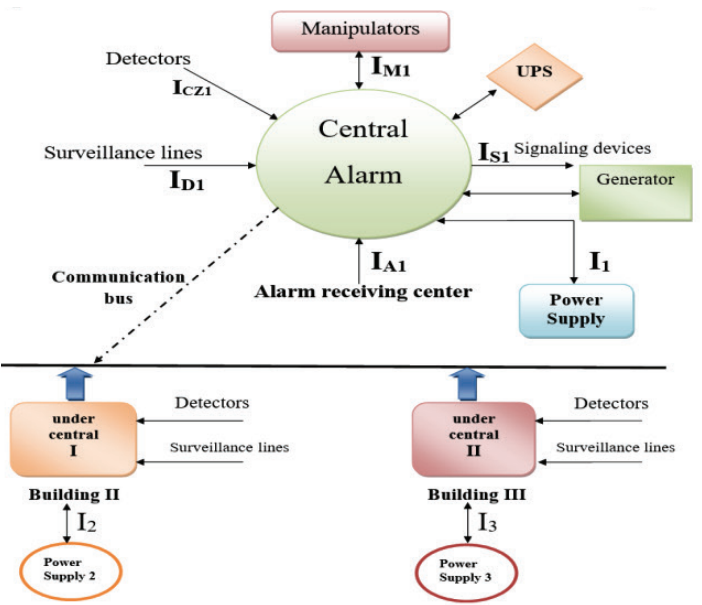

Fig. 5. Power consumption by the distributed access control system's device.

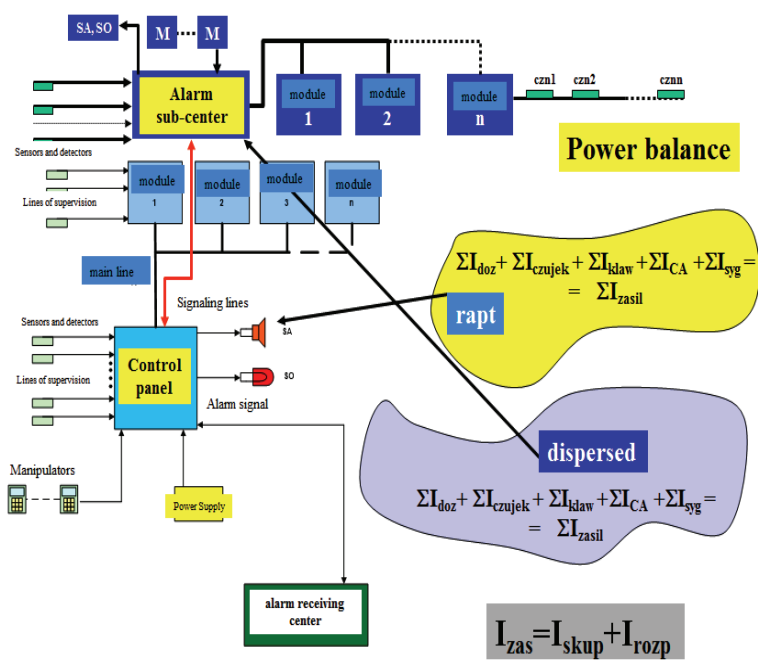

Fig. 6. Power supply implementation in the mixed access control system.

up the power balance for two types of the system operation - the state of monitoring and alarming. Taking into account the alarm system class - access control system (from 1 to 4 ), it is possible to determine the value of the capacity of backup power supply sources accumulators' batteries are the most commonly found in the systems.

\section{Reliability analysis of the power supply system used in the access control system in the vast area}

By analysing the operation of the power supply system used in the access control system, which is operated in the vast area, it can be stated, on the basis of the presented figures $3-6$, that it has a mixed reliability structure $[22,28,29]$. The damage to the main power supply of the system supplying the control panel results in the transition to the backup power supply. It results in the transition of the access control system from the state of complete usability $\mathrm{R}_{\mathrm{O}}(\mathrm{t})$ to the state of unreliability of safety $Q_{B}(t)$. During the main power supply failure, some functions of the access control system may be suspended, however, it does not affect safety in the vast area. The system's operation time on the backup power supply is determined by the internal battery capacity, which is specified for given values of the quiescent and alarm currents of sensors and actuators. If the power supply from the electrical grid is not reactivated at that time (main power supply failure), the access control system changes to the state of unreliability of safety $\mathrm{S}_{\mathrm{B}}[30]$. The access control system is used in the vast area - Fig. 5 has three control panels, mutually configured and monitored by the alarm centre. The power supply of individual control subpanels is implemented in a similar manner - the main power supply, the accumulators' battery. However, in case of the main power supply failure, the connections that can be used for mutual electricity exchange were not foreseen in the system. Fig. 7 illustrates the relationships in the considered access control system in terms of safety.

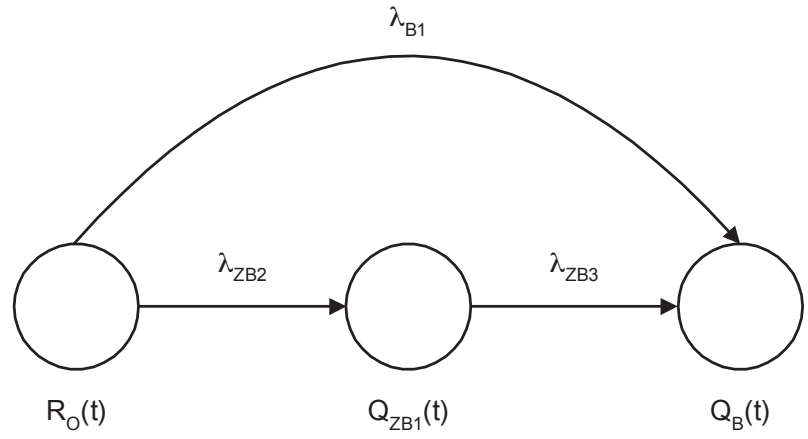

Fig. 7. Relationships in the power supply system of electronic safety systems. Markings in Fig.: $\mathrm{R}_{\mathrm{O}}(\mathrm{t})$ - probability function of the system's staying in the state of complete usability $\mathrm{S}_{\mathrm{PZ}}$, $\mathrm{Q}_{\mathrm{ZB}}(\mathrm{t})$ - probability function of the system's staying in the state of impendency over safety $S_{Z B}, Q_{B}(t)$ - probability function of the system's staying in the state of unreliability of safety $S_{B}, \lambda_{B 1}-$ intensity of transitions of the automatic transfer switching equipment, $\lambda_{\mathrm{ZB} 2}, \lambda_{\mathrm{ZB} 3}$ - intensity of transitions of external power lines and uninterruptible power supply. 
The system presented in Fig. 7 can be described by the following Chapman-Kolmogorov equations:

$$
\begin{aligned}
& R_{0}^{\prime}(t)=-\lambda_{B 1} \cdot R_{0}(t)-\lambda_{Z B 2} \cdot R_{0}(t) \\
& Q_{Z B 1}^{\prime}(t)=\lambda_{Z B 2} \cdot R_{0}(t)-\lambda_{Z B 3} \cdot Q_{Z B 1}(t) \\
& Q_{B}^{\prime}(t)=\lambda_{B 1} \cdot R_{0}(t)+\lambda_{Z B 3} \cdot Q_{Z B 1}(t)
\end{aligned}
$$

Assuming baseline conditions:

$$
\begin{aligned}
& R_{0}(0)=1 \\
& Q_{Z B 1}(0)=Q_{B}(0)=0
\end{aligned}
$$

and using certain mathematical transformations[31] (including the Laplace transform), the following relationships are obtained:

$$
\begin{gathered}
R_{0}(t)=e^{-\left(\lambda_{B 1}+\lambda_{Z B 2}\right) \cdot t} \\
Q_{Z B 1}(t)=\lambda_{Z B 2} \cdot\left[\frac{e^{-\left(\lambda_{B 1}+\lambda_{Z B 2}\right) \cdot t}-e^{-\lambda_{Z B 3} \cdot t}}{\lambda_{Z B 3}-\lambda_{B 1}-\lambda_{Z B 2}}\right] \\
Q_{B}(t)=\frac{\lambda_{B 1} \cdot\left[1-e^{-\left(\lambda_{B 1}+\lambda_{Z B 2}\right) \cdot t}\right]+}{\lambda_{B 1}+\lambda_{Z B 2}} \\
+\lambda_{Z B 2} \cdot \lambda_{Z B 3} \cdot\left[\begin{array}{l}
\frac{e^{-\left(\lambda_{B 1}+\lambda_{Z B 2}\right) \cdot t}}{\left(\lambda_{B 1}+\lambda_{Z B 2}\right) \cdot\left(\lambda_{B 1}+\lambda_{Z B 2}-\lambda_{Z B 3}\right)} \\
-\frac{e^{-\lambda_{Z B 3} \cdot t}}{\left(\lambda_{B 1}+\lambda_{Z B 2}-\lambda_{Z B 3}\right) \cdot \lambda_{Z B 3}}+ \\
+\frac{1}{\left(\lambda_{B 1}+\lambda_{Z B 2}\right) \cdot \lambda_{Z B 3}}
\end{array}\right]
\end{gathered}
$$

The received relationships make it possible to determine the probabilities of the power supply system's staying $n$ the state of complete usability $\mathrm{R}_{\mathrm{O}}$, impendency over safety $Q_{z B}$ and unreliability of safety $Q_{B}$.

By applying the relationships $(3 \div 5)$, it is possible to determine the probability values of the power supply system's staying in the distinguished states. Such a procedure is shown in the following example.

Example

Assuming the following values describing the analysed system:

- operation time - 1 year:

$$
\mathrm{t}=8760[h]
$$

- intensity of transitions from the state of complete usability $\mathrm{S}_{\mathrm{PZ}}$ to the state of impendency over safety $\mathrm{S}_{\mathrm{ZB} 1}$ :

$$
\lambda_{\mathrm{ZB} 2}=0.0000003429\left[\frac{1}{h}\right]
$$

- intensity of transitions from the state of impendency over safety $S_{Z B 1}$ to the state of unreliability of safety $S_{B}$ :

$$
\lambda_{\mathrm{ZB} 3}=0.0000002285\left[\frac{1}{h}\right]
$$

- intensity of transitions from the state of complete usability $\mathrm{S}_{\mathrm{PZ}}$ to the state of unreliability of safety $\mathrm{S}_{\mathrm{B}}$ :

$$
\lambda_{\mathrm{B} 1}=0.0000001142\left[\frac{1}{h}\right]
$$

Transition rate value $\lambda=0.0000003429\left[\frac{1}{h}\right]$ corresponds to reliability $\mathrm{R}=0.997$.

Transition rate value $\lambda=0.0000002285\left[\frac{1}{h}\right]$ corresponds to reliability $\mathrm{R}=0.998$.

Transition rate value $\lambda=0.0000001142\left[\frac{1}{h}\right]$ corresponds to reliability $\mathrm{R}=0.999$.

For the above input values using the equations $(3 \div 5)$, it is possible to obtain:

$$
\begin{aligned}
& R_{0}=0.997002 \\
& Q_{Z B 1}=0.001996 \\
& Q_{B}=0.001002
\end{aligned}
$$

The obtained values allow for reliability assessment of the analysed power supply system.

\section{Conclusions}

The issue presented in the article concerned the reliability analysis of the power supply system of the access control systems, which are operated in a large facility. The power supply system, which consists of two dependent power supply systems, was analysed. The first system is the power supply, which implements its function by the control panel (subpanel).

The second system includes the accumulators' batteries located in individual subsystems of the access control system - Fig. 5. The technical parameters of the power supply and accumulators' batteries (current, output voltages, etc.) are controlled by individual control panels, and the information on its technical condition is transmitted to the alarm receiving centre. The individual subsystems of the access control system can be treated as independent due to the implemented power supply function.

According to legal regulations, the power supply of individual subsystems should be implemented from separate electric circuits (main cable connector) appropriately protected by overvoltage and short-circuit. As a result of the adopted assumptions, the calculations, which allow to determine the probability values of the power supply system's staying in the distinguished states, were carried out. The calculations can be useful for assessing various types of power supply systems' solutions and rational selection, with assumed initial conditions and selection criteria.

In the further studies, it is planned to conduct further reliability analyses that take into account other types of the power supply systems - e.g. UPS. 


\section{References}

1. J. Paś, Prz. Elektrotechniczny 10, 91 (2015)

2. E. Pilo, (editor), Power supply, energy management and catenary problems (WIT Press, 2010)

3. L. Wang, (editor), Modeling and control of sustainable power systems (Springer-Verlag, 2012)

4. L. Będkowski, T. Dąbrowski, The basis of exploitation, part II: The basis of exploational reliability (Military University of Technology, Warsaw, 2006)

5. J. Dyduch, J. Paś, A. Rosiński, The basic of the exploitation of transport electronic systems (Publishing House of Radom University of Technology, Radom, 2011)

6. M. Krzykowski, Polityka Energetyczna - Energy Policy J. 17, 3, (2014)

7. M. Siergiejczyk, J. Paś, A. Rosiński, IET Intell Transp Sy. 10, 9, DOI: 10.1049/iet-its.2015.0183 (2016)

8. M. Siergiejczyk, J. Paś, A. Rosiński, Modeling of process of exploitation of transport telematics systems with regard to electromagnetic interferences, in Tools of Transport Telematics, given as the monographic publishing series "Communications in Computer and Information Science”, 531 (Springer-Verlag, pp. 99-107, 2015)

9. T. Dabrowski, M. Bednarek, K. Fokow, M. Wisnios, Prz. Elektrotechniczny 88, 11A (2012)

10. J. Paś, M. Siergiejczyk, Diagnostyka, 17, 1 (2016)

11. J. Wiatr, A. Boczkowski, M. Orzechowski, Overvoltage protection, selecting wires and their protection in low voltage wiring systems (MEDIUM Publishing House, Warsaw, 2010)

12. M. Siergiejczyk, J. Paś, A. Rosiński, Kones. 23, 3, (2016)

13. J. Wiatr, M. Miegon, UPS power supplies and accumulator batteries in emergency power systems. (MEDIUM Publishing House, Warsaw, 2008)

14. P. Łubkowski, D. Laskowski, The selected issues of reliable identification of object in transport systems using video monitoring services, in the monograph Telematics - support for transport, given as the monographic publishing series - „Communications in Computer and Information Science”, vol. 471, Springer-Verlag, pp. 59-68 (2014)

15. J. Paś, Operation of electronic transportation systems (Publishing House University of Technology and Humanities, Radom, 2015)

16. R. Burdzik, Ł. Konieczny, T. Figlus, Concept of onboard comfort vibration monitoring system for vehicles, in Activities of Transport Telematics, vol. 395, Springer, pp. 418-425 (2013)

17. M. Wiśnios, T. Dąbrowski, M. Bednarek, Prz. Elektrotechniczny 91, 10 (2015)

18. M. Wiśnios, T. Dąbrowski, J. Konbin 29, 1 (2016)
19. M. Kuchta, M. Siergiejczyk, J. Paś, Vibroeng. 18, 7 (2016)

20. D. Laskowski, P. Łubkowski, E. Pawlak, P. Stańczyk, Anthropotechnical systems reliability, in Safety and Reliability: Methodology and Applications - Proceedings of the European Safety and Reliability Conference ESREL 2014, CRC Press/Balkema, London, pp. 399-407 (2015)

21. M. Stawowy, P. Dziula, Comparison of uncertainty multilayer models of impact of teleinformation devices reliability on information quality, in Proceedings of the European Safety and Reliability Conference ESREL 2015, CRC Press/Balkema, pp. 2685-2691 (2015)

22. M. Stawowy, Model for information quality determination of teleinformation systems of transport, in Proceedings of the European Safety and Reliability Conference ESREL 2014, CRC Press/Balkema, pp. 1909-1914 (2015)

23. M. Siergiejczyk, K. Krzykowska, A. Rosiński, Reliability assessment of cooperation and replacement of surveillance systems in air traffic, in Proceedings of the Ninth International Conference Dependability and Complex Systems DepCoSRELCOMEX, given as the monographic publishing series - Advances in intelligent systems and computing", (Springer, pp. 403-411 (2014)

24. M. Siergiejczyk, K. Krzykowska, A. Rosiński, Reliability assessment of integrated airport surface surveillance system, in Proceedings of the Tenth International Conference on Dependability and Complex Systems DepCoS-RELCOMEX, given as the monographic publishing series - „Advances in intelligent systems and computing", vol. 365, Springer, pp. 435-443 (2015)

25. A. Rosiński, Modelling the maintenance process of transport telematics systems (Publishing House Warsaw University of Technology, Warsaw, 2015)

26. A. Rosiński, Reliability analysis of the electronic protection systems with mixed - three branches reliability structure, in International Conference European Safety and Reliability, ESREL 2009, pp. 1637-1641 (2009)

27. M. Kłodawski, K. Lewczuk, I. Jacyna-Gołda, J. Zak, Arch Transp. 41, (2017)

28. A. Rosiński, Design of the electronic protection systems with utilization of the method of analysis of reliebility structures, in Nineteenth International Conference On Systems Engineering (ICSEng 2008), Las Vegas, USA, pp. 421-426 (2008)

29. A. Rosiński, Reliability analysis of the electronic protection systems with mixed $\mathrm{m}$-branches reliability structure, in International Conference European Safety and Reliability, ESREL 2011, pp. 2064-2071. (2011)

30. R. Billinton, R.N. Allan, Reliability evaluation of power systems (Plenum Press, New York, 1996)

31. Zajkowski K., Neural Comput Appl. 24, 2, (2014) 